\title{
MORPHOLOGY OF THE BLOOD IN EPIDEMIC PAROTITIS *
}

\author{
JOSEPH H. BARACH, M.D. \\ PITTSBURGH, FA.
}

Perhaps it is because of our general disregard of its importance as a disease that so little work has been done on the morphology of the blood in epidemic parotitis. From such a viewpoint it is true that a perfect knowledge of the pathological physiology of the disease is of comparative little import. But this disease, it has been observed, is accompanied by a lymphocytosis, and the problem of lymphocytosis is an interesting and important one. The blood-picture of this disease is also of distinct value in differential diagnosis.

A perusal of the literature on the blood-picture in this disease shows it to be very fragmentary; so that there is need for summarizing and a proper correlation of the results obtained by the various observers.

Since the work of Wile, ${ }^{1} \mathrm{I}$ have been unable to find any noteworthy contributions. Wile's bibliography refers to the work of Cabot, ${ }^{2}$ who notes an absence of leukocytosis in this disease. Sasquépéé ${ }^{3}$ notes a slight leukocytosis, low polynuclears, increased mononuclears, a decreased eosinophil count and in complicating orchitis a leukocytosis. Krestnikow ${ }^{4}$ records a lymphocytosis, mononuclear increase, and in complicating orchitis a polynuclear increase. Pick ${ }^{5}$ found a leukopenia, increased mononuclears, decreased polynuclears and decreased eosinophils, in the orchitis a leukopenia. 'Turck ${ }^{6}$ found a leukocytosis and eosinophilia. Wile found a lymphocytosis relative and absolute; eosinophils first lessened, later increased; polynuclears varying with the mononuclears. Complicating orchitis causing a tendency to polynuclear increase.

From these findings it appears that there is manifestly a lack of agreement among the observers as to what is the actual blood-picture. Some of the observers record a leukocytosis, while the others did not find it. A like difference of opinion exists with regard to the mononiclears and the eosinophils.

* Submitted for publication Oct. 21, 1913.

1. Wile: Arch. Pediat., xxiii, 674.

2. Cabot: Clinical Examination of the Blood. (Ed. 5.)

3. Sacquépéé: Arch. de mél. exper., 1902.

4. Krestnikow: Thèse de St. Petersburg, 1902.

5. Pick: Wien. klin. Rundschau, 1902.

6. Turck: Verhalten des Blutes bei acuten Infections-Krankheiten. 
In this work, as in my work on pertussis, ${ }^{7}$ I aimed to determine the successive changes in the leukocyte formula by studying the same cases throughout the disease, and after it had subsided, correlating these findings with the daily clinical notes.

\section{MATERIALS}

The eleven patients who come into this consideration were residents of the Industrial Home for Crippled Children, ranging in age from 9 to 20 years. Five of them were males.

Their general health had previously been good, and they were all free from such other disease activity at the time this epidemic appeared as might affect their cell counts.

\section{PRECAUTIONS}

The specimens were taken about an hour before meal time; thus avoiding a digestive leukocytosis. Another precaution was the counting of blood taken from both the lobe of the ear and the finger. On account of the proximity of the usual site for getting the specimens to the area of pathologic activity, it occurred to me that possibly the blood in such an hyperemic zone might be influenced more or less. But in a number of cases the blood-pictures were practically the same in both specimens.

\section{METHOD}

'The first blood-count was made just as soon as the cases were suspected. At this time there was slight enlargement of the cervical and submaxillary lymph-nodes and perhaps a slight rise in temperature.

The second count was made on full development of the swelling, and the third when the temperature reached normal and the swelling was subsiding. Usually the temperature reached normal several days before the swelling subsided. After that, one or two counts were made at intervals of a week.

\section{CONTROLS}

It was impossible to get control counts prior to the onset of the disease, as there was no way of knowing who was exposed; but control counts were taken six months after the disease subsided when the children were in good health.

As a working formula for what should have been normal for these children, I assume that a leukocyte count of 8,000 and polynuclear of 72 per cent., lymphocytes 22 per cent., large mononuclears 3 per cent., transitionals 1 per cent., eosinophils 2 per cent., is about normal. If we count the lymphocytes and large mononuclears together, we have a mononuclear count of 25 per cent., and therefore 2,000 mononuclears to

7. Barach, Joseph H.: Morphology of the Blood in Pertussis, The Archives INT. MED., 1908, i, 602. 
the cubic millimeter. If a patient had 3,000 mononuclears, the figures read 50 per cent. increase and so on.

\section{TOTAL LEUKOCYTF CONNTS}

At the onset of the disease, when the patient is having mild constitutional symptoms and enlargement of submaxillary glands, but has not yet developed parotid swelling, the examination in two cases showed a leukopenia. One patient of 13 years showed a leukocyte count of 5,280 per c.mm., another of 20 years had 5,200 leukocytes.

During the height of the disease, when the parotid gland is swollen to its maximum, in the entire series the largest count was $\%, 800$, the lowest was 4,000 , the average being 5,700 per c.mm. This average is lower than my findings in a series of 150 cases of typhoid fever, in which leukopenia is one of the characteristic features. On studying the temperature charts and clinical notes in these cases I find that those which had the higher fever and greoter parotid involvement showed the most marked leukopenia. In five cases in which the patients had most of the involvement on one side at the time of the examination, the count ranged between 6,100 and 7,800 per c.mm. In the remaining six, in whom both sides were equally large, and nuch larger than in the unilateral cases, the counts ranged between 5,000 and 5,680 per c.mm.

Leukocyte Count When Swelling Recedes.-By the time the parotid swelling was markedly diminished, which usually occurred between the fifth and seventll days of the disease, almost invariably the leukocyte count showed a cell increase.

Leukocyte Counts After Swelling Subsided.-In the counts made about a week after the swelling had subsided, the number of leukocytes seemed to vary, upward in half and down in the others. In the first half the leukocytes steadily increased toward the normal. In the other's, their number oscillated.

Leukocyte Count Six months Later.-At this time when the children were all in their normal health, the leukocyte counts in every instance was considerably higher than during the activity of the disease. The average for the series being 7,920 per c.mm. as compared with 5,700 per c.mm. during the activity of the disease.

Polynuclears.--In not one case was there an absolute and relative increase of these cells throughout the attack. Two cases did show a relative increase in the early days of the disease.

In all cases as the parotitis subsided the polynuclears increased toward their normal number. Later counts showed irregularity as to the number of cells, but the counts were always higher than during the activity of the disease. 
Mononuclears.-These were constantly abore normal, except in two cases, which showed a decrease early in the disease.

The two exceptions behaved as follows: At the first three counts in one case there was a decrease in mononuclears of 5 per cent. to 2 per cent. and 10 per cent., while the three following counts showed an increase over normal of 33 per cent., 75 per cent. and 75 per cent.

In the second case, a young lady of 20 , the mononuclears were decreased 25 per cent. and 5 per cent. at the first and second counts, but the third and fourth counts gave an increase of 5 per cent. and 30 per cent. in the mononuclears. These appear to be cases in which the blood reaction to the disease is delayed.

The Eosinophils.-Nearly all cases showed more of these cells after the disease had subsided than during its activity. But the total numbers and their proportions did not seem to present any definite course.

Other Cells.-Transitionals and mast-cells did not seem conspicuous in any of the counts. Nor did $\Upsilon$ notice any pathologic leukocytes, such as are occasionally found.

This series presented no opportunity for observing the effect of the complications of the disease on the blood formula.

\section{SUMMARY}

In uncomplicated cases of epidemic parotitis the leukocytes are affected in the following manner:

By the time the disease has manifested itself - even though the parotitis is not yet developed - a leukopenia is present. The number of lymphocytes is moderately increased and the polynuclears have fallen below normal. When the parotitis is fully developed there is a marked leukopenia, most marked in the cases with the higher temperature and greater parotid involvement. In this leukopenia the polynuclears are relatively and absolutely decreased, the mononuclears are relatively and absolutely increased.

As the disease subsides the total number of leukocytes, the polynuclears and mononuclears revert toward their normal proportion. The eosinophils, which are scarcely seen during the activity of the disease, are found in about their usual numbers as the blood returns toward the normal.

4502 Fifth Avenue. 